\title{
Dependence of the Possible and Allowable Projection Error on the Projection Time Frame
}

\author{
Yu.D. Kononov, D.Yu. Kononov*
}

Melentiev Energy Systems Institute of Siberian Branch of Russian Academy of Sciences, Irkutsk, Russia

\begin{abstract}
This study addresses the issues of assessing and factoring in the effect of uncertainty growth on the possible performance of projections and their allowable errors. Relying on projects of nuclear power plants and combined cycle power plants as a case study, we assess the dependence of their economic performance indicators on possible changes in the conditions of their future operation in a given year. To assess the effect of the range and nature of input data uncertainty on the projections of the development of regional energy supply systems, we proposed a methodological toolkit that combines optimization with the Monte Carlo simulation. Its application to one of the options for commissioning new power plants in European Russia enabled us to estimate the possible response of the average and marginal cost of electricity in this aggregated region to the broadening of the uncertainty range of the gas price. We note that the assessment and comparison of the possible error of projected indicators with the requirements for their accuracy in making priority investment and other decisions facilitate the justification of the acceptable complexity of employed models and projection methods.
\end{abstract}

Index Terms: projections, electric power industry, uncertainty, reliability.

\footnotetext{
${ }^{*}$ Corresponding author.

E-mail: kononov@isem.irk.ru
}

http://dx.doi.org/10.38028/esr.2021.01.0001

Received March 06, 2021. Revised March 19, 2021.

Accepted March 30, 2021. Available online May 26, 2021.

This is an open access article under a Creative Commons Attribution-NonCommercial 4.0 International License.

C) 2021 ESI SB RAS and authors. All rights reserved.

\section{INTRODUCTION}

As the projection time frame extends into the future, this increases the uncertainty of future conditions of the energy industry development and compromises the performance of long-term projections, i.e., Their reliability, accuracy, and value.

Published projections of energy development in the USA and Europe to 2030-2035 compellingly demonstrate the nonlinear nature of growth of the uncertainty range as the projection time frame extends. For example, in the U.S. Energy projections [1], the uncertainty range for primary energy consumption volumes for all cases covered by the projections grows from the low $5-10 \%$ for the 5 -year time frame to the high $13-23 \%$ and $22-38 \%$ for the projections for 15 and 25 years, respectively.

In "The energy strategy of Russia to 2030” (es-2030), as approved in 2009 (es-2030), the difference between the total energy consumption under the worst- and bestcase scenarios amounts to $7 \%$ for the first 5 years and subsequently grows to $22 \%$ and $31 \%$ for the projections for 15 and 20 years into the future, respectively.

A key performance indicator of the projections is their reliability, which can be characterized by an uncertainty range, i.e., The percentage difference between the highest and lowest values of a projected variable, as well as the coefficient of variation and dispersion (spread) of the values of projected variables set against their mean values or reference case values. The width of the range within which the projected system parameters can fluctuate determines the accuracy of the projection.

Statistical methods of estimating the projection error are well-known and widely used in practice (e.g., [2, 3]). However, they are suitable mainly for past projections or those of the dynamics of individual indicators based on their trends. When projecting the development of such 
Table 1. Deviation of the electricity cost from its value in the deterministic case of the projection when the uncertainty range increases for the gas price, $\%$

\begin{tabular}{|c|c|c|c|c|}
\hline \multirow{2}{*}{ Federal district } & \multirow{2}{*}{ Cost } & \multicolumn{3}{|c|}{ Uncertainty range } \\
\hline & & $15 \%$ & $30 \%$ & $50 \%$ \\
\hline \multirow[b]{2}{*}{ Central } & Average & 2.4 & 3.7 & 4.8 \\
\hline & Marginal & 3.9 & 7.5 & 13.1 \\
\hline \multirow{2}{*}{ Northwestern } & Average & 2.5 & 4.1 & 5.1 \\
\hline & Marginal & 3.8 & 7.5 & 12.6 \\
\hline \multirow{2}{*}{ Southern } & Average & 3.1 & 5.9 & 9.1 \\
\hline & Marginal & 3.3 & 7.8 & 13.0 \\
\hline \multirow{2}{*}{ Ural } & Average & 0.9 & 1.5 & 2.5 \\
\hline & Marginal & 3.5 & 7.1 & 12.1 \\
\hline \multirow{2}{*}{$\begin{array}{l}\text { The aggregated region as a } \\
\text { whole }\end{array}$} & Average & 1.1 & 3.1 & 4.6 \\
\hline & Marginal & 3.5 & 7.4 & 12.4 \\
\hline
\end{tabular}

Note. Calculations for one of the development options of regional energy supply systems in european russia in 2030-2035.

complex systems as the energy sector of a country or its regions, it becomes important to assess not only the likely and unavoidable error but also the allowable error of the projection. As of now, there are no generally accepted and universally applicable methods that would facilitate such an assessment.

In what follows, relying on the example of a projection of the development of power supply systems, we consider possible approaches to assessing the acceptable requirements for the quality of projections.

\section{ESTIMATING THE UNAVOIDABLE ERROR}

The inevitable error of projections of the dynamics of certain indicators depends to a greater extent on the error of the input data used in the calculations. It is possible to capture this dependence in the form of a regression equation with sufficient confidence only for a specific and very simple system. For example, the dependence of the average cost of electricity generation by existing power plants in the region on the range of uncertainty of the cost of gas lends itself to such a description. However, a gross error proves inevitable when assessing the projection error of the dynamics of this indicator while taking into account the effect of gas prices on the mix of new capacity additions under changing conditions.

Optimization models (e.g., $[4,5])$ are deemed suitable for incorporating this effect, for assessing the sensitivity of projections of the development of complex systems such as the energy sector to possible changes in individual input data. The minimum cash cost of meeting a given demand for energy carriers serves as the criterion of optimality in such models. Based on their change when varying different indicators, we can judge possible and allowable error in the projections of these indicators and their significance.

In the case that necessitates taking into account the effect of the uncertainty of several interrelated input data variables on the reliability of the projection of the development of the energy sector or the systems of its individual industries, the stochastic models [6] combining the optimization with the well-known Monte Carlo method [7] can be instrumental. Such a model is used, for example, in projections of generation costs [8], electricity prices [9], and energy markets [10].

The Monte Carlo method combined with optimization is used in the miss-el model [11]. It was used to assess the effect of a range of uncertainty of gas prices and other indicators on the electricity cost in European Russia including the Urals. The calculations were performed given interval-valued input data and the normal distribution of their probable values within the specified ranges. In this case, only the gas price uncertainty range was varied. The calculation results were compared against the deterministic case.

The broadening of this range leads to an increase in the average gas price and causes a change in the mix of new power plant capacity additions, which affected the cost of electricity generation. Marginal cost, i.e., The discounted cost of electricity generation at the most expensive power plants of those to be commissioned, grows particularly significantly and nonlinearly. As the table shows, with a 50 percent increase in gas price uncertainty, the average price in the European part of the country could increase by 4-5 percent, and the marginal one - by more than 12 percent (under the assumed projection conditions). At the same time, there is a noticeable difference in the response of individual federal districts to the uncertainty in gas prices.

Additional calculations with the MISS-EL model were performed assuming the uniform probability distribution of the gas price within the same ranges as under its normal distribution. The calculation results did not affect the conclusion claiming a noticeable and growing unavoidable projection error as the uncertainty range of the key input data increases.

\section{THE ALLOWABLE PROJECTION ERROR}

The allowable projection error depends on the aims of the projection and its importance for making strategic decisions by investors, the state, and society. Its numerical value is primarily determined by the probable damage (economic, environmental, or social) due to the projection error. 

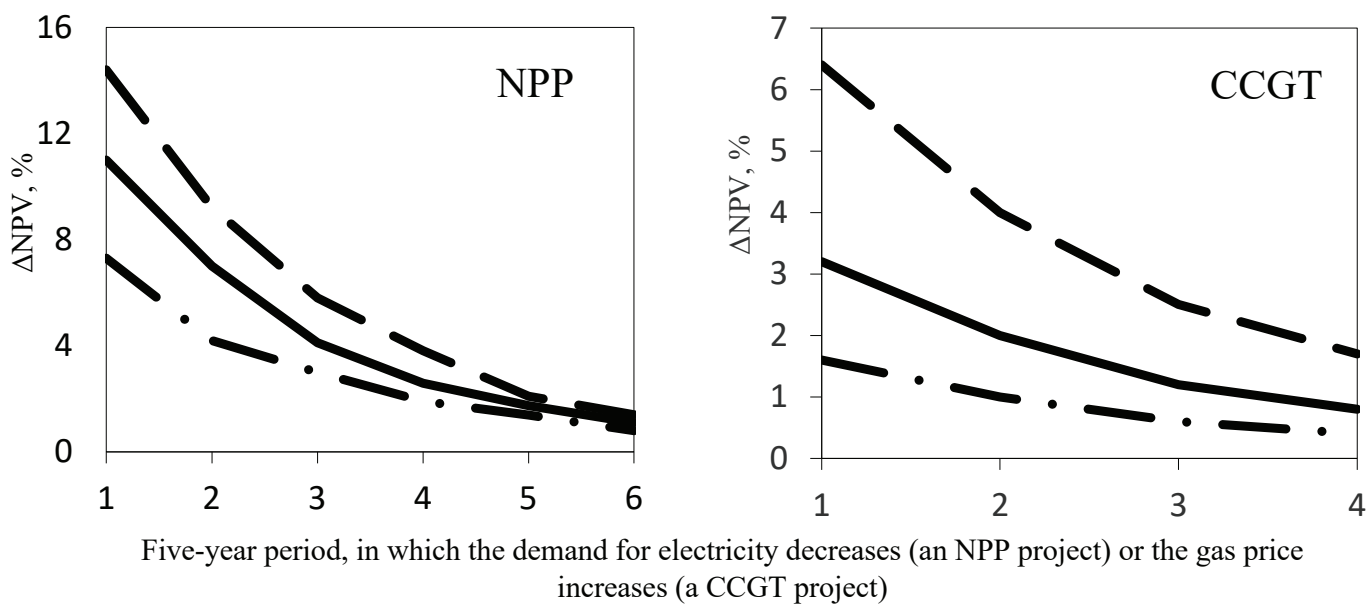

Fig. 1. Effect of changes (error) in previously projected conditions on the decrease in the economic performance of power plant projects. In one of the five-year periods. Note. We considered a range of change in electricity demand by 10-20\% and that in gas prices by $25-100 \%$ (the lower and upper boundaries in the figure, respectively).

For the investor (company), the damage is usually measured by a decrease in expected profits. The damage for the state can be characterized by a possible decline in budget revenues, living standards of the population, and economic growth rates. In this case, one has to set an allowable change in the value of the employed optimality criterion by relying on expert judgment. When projecting the development of the energy sector under the considered scenarios, such a criterion is, as a rule, the minimum cost of meeting a given demand for energy carriers.

It is difficult to judge the error of the system development projection with no estimate of the allowable error of the expected dynamics of the key projected indicators. Such indicators in the energy sector projections are energy demand and prices, the development of regional energy supply systems and new technologies, and the extent to which energy security requirements are met.

As the time frame in question increases, the requirements for reliability and accuracy of projections decrease, which is due to an exponential rise in the uncertainty of conditions, a decrease in the importance of the projection results for making priority decisions, an increase in the opportunities (time margin) to prevent the anticipated threats.

When making investment decisions in the energy sector, one of the primary objectives is to assess the efficiency and risks of large-scale capacity addition projects in the electric power industry or the fuel industry. The investor values the revenues of a more distant future less than those of an immediate one, which is reflected in the discounting of indicators that measure the financial performance of projects: net present value (npv), internal rate of return, payback period, and others.

By varying the values of key input data variables for any of the periods within the projection time frame and by tracing the effect of such variations on the project value, we can get an idea of an acceptable decrease in the projection accuracy as these periods gradually extend further into the future.

This approach was applied in the analysis of the sensitivity of the performance of nuclear power plant project to a possible variation in electricity demand (electricity production) over time and sensitivity of the performance of combined cycle power plant project to a change in gas prices.

The calculation results shown in the figure indicate a marked nonlinear decrease in this sensitivity as the time of these changes gets more remote from the present.

Given the assumed input data, fluctuations in electricity demand as low as those within the range of $15-20 \%$ have a noticeable impact on the net present value only in the first 15 years of the projection period under consideration. Consequently, the requirements for the accuracy of projecting the utilized capacity of the nuclear power plant at the end of its service life also get less stringent. The required reliability of gas price projections for valuation of the ccgt project in the third five-year period is two times lower than in the first one. The increase in the discount rate (in the calculations it was taken to be equal to $10 \%$ ) further reduces the requirements for the accuracy of longterm projections of the indicators that affect the valuation of projects.

\section{CONCLUSION}

The estimation and comparison of the likely error for the projected variables against the requirements of their accuracy (reliability), when making investment and other decisions, facilitate a more well-grounded choice of the acceptable level of complexity of employed economic and mathematical models. Should an elaboration of these models, when compared against the currently employed models, lead to a change in the solution (i.e., The projection) by a magnitude less than the allowable error, the appropriateness of such innovation is anything but obvious. 
The methods to assess the quality and value of the input data, the requirements set for such data, and the reliability of energy projections for various time frames need further development. To this end, one should consider the specific features of problems to be solved within a given projection.

The study was carried out under a state assignment project (no. FWEU-2021-0003 reg. No. AAAA-A21-121012090014-5) of the program for basic research of the russian federation for 2021-2030.

\section{REFERENCES}

[1] Annual Energy Outlook [Electronic publication] / U.S. Energy Information Administration. Available at: http://www.eia.gov/forecasts/aeo/ (1999-2014)

[2] L.N. Slutskin. An MBA course on forecasting in business. Moscow: Alpina Business Books, 2006, 277 p. (in Russian)

[3] A. Dovydenko, R. Fildes. "Measuring forecasting accuracy: The case of judgmental adjustments to SKU - level demand forecasts," International Journal of Forecasting, no. 29, pp. 510-522, 2013.

[4] A.V. Lagerev. "A dynamic territorial and production model for the development of scenarios of mutually aligned development of Russia's energy industry as concerns its federal subjects," Izvestija RAN, Energetika, no. 4, pp. 26-32, 2004. (in Russian)

[5] S.Messner, M. Strubegger. User's Guide for MESSAGE III/WR-95-69. IIASA, Laxenburg, Austria, 1995.

[6] Kurt Marti. Stochastic Optimization Methods. Springer, 2005, 317 p.

[7] S.M. Ermakov. Monte Carlo methods and related problems. Moscow: Nauka, 1975, 472 p. (in Russian)

[8] J. Valenzuela, M. Muzumdar. "Monte Carlo Computation of Power Generation Production Cost Under Operating Constraints," IEEE Transactions on Power Systems, vol. 16, no. 4, Nov. 2001.

[9] A. Poullikkas. "An adaptive long-term electricity price forecasting modeling using Monte Carlo simulation," Journal of Power Technologies, vol. 98, no. 3, pp. 207-273, 2018.

[10] M. Amelin, L. Soder. “On Monte Carlo Simulation of Electricity Markets with Uncertainties in Precipitation and Loud Forecasts," in IEEE Porto Power Tech Proceedings, vol. 1, Porto, 2001.

[11] Yu.D. Kononov, V.N. Tyrtyshnyi, D.Yu. Kononov. "The application of stochastic modeling in choosing regional energy supply options while addressing investment risks," Informatsionnye i matematicheskie tekhnologii $\mathrm{v}$ nauke i upravlenii (Information and Mathematical Technologies in Science and Management), no. 2(10), pp. 80-87, 2018. (in Russian)

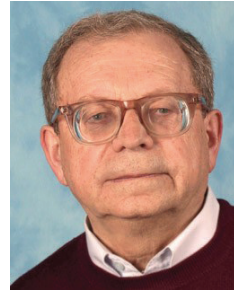

Yuri Kononov - Doctor of Economics, Professor, Honored Worker of science of the Russian Federation, chief researcher of Melentiev Energy Systems Institute of Siberian Branch of the Russian Academy of Sciences, Russia, Irkutsk. His research interests are modeling and research of interaction between energy and economy; methods to enhance the validity of long-term forecasts of energy development.

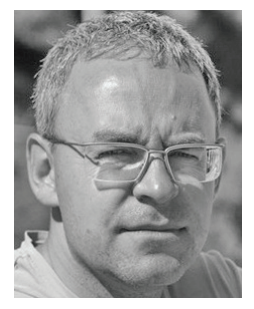

Dmitry Kononov - Ph. D., Senior researcher of Melentiev Energy Systems Institute of Siberian Branch of the Russian Academy of Sciences, Russia, Irkutsk. His research interests are consideration of the impact of the uncertainty factors on the methods for the evaluation of strategic threats to power industry development. 